\title{
Dermatological Conditions Among the Geriatric Population : A Cross Sectional Survey
}

\section{Mubashar Mashqoor Mir' ${ }^{1}$, Mohammad Sarwar Mir ${ }^{2}$}

${ }^{1}$ Post Graduate Resident, Post Graduate Department of Dermataology, GMC Jammu

${ }^{2}$ Senior Resident, Department of Hospital Adminstration, SKIMS, Srinagar.

*Corresponding Author: Dr. Mubashar Mashqoor Mir, Post Graduate Resident, Post graduate Department of Dermataology, GMC Jammu.

\section{Abstract}

Background: Geriatric health care has been considered as an emerging issue due to the increase in life expectancy. Cutaneous lesions are more common among the elderly due to aging, which causes decline in the function of skin.

Objective: To determine the spectrum of dermatological manifestations among the elderly.

Materials and Methods: A total of 200 patients aged 60 years and above reporting to the health camp. Skin changes in all the patients were recorded and were classified into physiological and pathological changes.

Results: Among 200 patients studied, 72\% were men and 28\% were women. Eczema (44\%) was the most common pathological condition followed by pruritus (38\%), and xerosis was common among the physiological changes.

Conclusion: Geriatric population are one of the more vulnerable sections of our society. Majority of the elderly in this study had xerosis and eczema.

Keywords: Geriatric; cutaneous manifestation; eczema

\section{INTRODUCTION}

In the twenty-first century, one of the biggest social transformations is population aging. ${ }^{1}$ The global share of older people (aged 60 years or above) increased from $9.2 \%$ in 1990 to $11.7 \%$ in 2013 , and will continue to grow as a proportion of the world population, reaching $21.1 \%$ by 2050 . At present, about two-thirds of the world's older persons live in developing countries. By 2050, nearly 8 in 10 of the world's older population will live in the less developed regions. ${ }^{2}$ The most common problems in aging population are economic, psychosocial, mental, and medical morbidities. Health has always been considered the primary concern in old age as aging predisposes elderly people to injuries and diseases. Skin diseases are common in elderly, and increased prevalence of skin disease may reflect underlying systemic diseases such as diabetes mellitus, neurological disease, vascular insufficiency and malignancy, and may also be due to restricted mobility/lack of care and compromised immune status. Because meeting health needs of the aging population is a priority and aging-related issue is drawing increasing attention in the present scenario, this study was undertaken to know the prevalence of skin problems among elderly. ${ }^{3}$

The main objective of this study was to determine the spectrum of cutaneous manifestations in geriatric population.

\section{MATERIALS AND METHODS}

A cross-sectional study was conducted among 200 elderly patients (aged group 60 years and above) attending health camp in June 2014.

A structured questionnaire was used to obtain the data regarding the socio-demographic profile after obtaining the informed consent. A detailed history of cutaneous complaint including associated medical conditions followed by general physical, systemic, and 
Dermatological Conditions Among the Geriatric Population : a Cross Sectional Survey

dermatological examinations were carried out for all the patients.

Skin changes in all the patients were recorded and were classified into physiological and pathological changes.

\section{RESULTS}

Among the 200 patients, 72\% (114) were men and $28 \%$ (56) were women.

Table 1. Distribution of physiological changes in geriatric population

\begin{tabular}{|l|l|l|}
\hline \multicolumn{1}{|c|}{ Condition } & Frequency & \multicolumn{1}{c|}{ Percentage } \\
\hline Xerosis & 180 & $90.0 \%$ \\
\hline Wrinkling & 174 & $87.0 \%$ \\
\hline $\begin{array}{l}\text { Idiopathic } \\
\text { guttate } \\
\text { hypomelanosis }\end{array}$ & 90 & $45.0 \%$ \\
\hline Atrophy of skin & 68 & $34.0 \%$ \\
\hline Dermatoheliosis & 64 & $32.0 \%$ \\
\hline
\end{tabular}

Table 2. Distribution of pathological changes in geriatric population

\begin{tabular}{|l|l|l|}
\hline Condition & Frequency & Percentage \\
\hline $\begin{array}{l}\text { Eczematous } \\
\text { dermatitis }\end{array}$ & 88 & $44.0 \%$ \\
\hline Pruritis & 64 & $32.0 \%$ \\
\hline $\begin{array}{l}\text { Neoplastic } \\
\text { changes }\end{array}$ & 48 & $24.0 \%$ \\
\hline Infections & 40 & $20.0 \%$ \\
\hline Psychodermatosis & 28 & $14.0 \%$ \\
\hline Photodermatosis & 24 & $12.0 \%$ \\
\hline $\begin{array}{l}\text { Cutaneous drug } \\
\text { reactions }\end{array}$ & 14 & $7.0 \%$ \\
\hline Misscalenous & 10 & $5.0 \%$ \\
\hline
\end{tabular}

\section{Discussion}

Health has always been considered the primary concern in old age as aging predisposes elderly people to injuries and diseases. Skin diseases are common in elderly, and increased prevalence of skin disease may reflect underlying systemic diseases such as diabetes mellitus, neurological disease, vascular insufficiency and malignancy, and may also be due to restricted mobility/lack of care and compromised immune status.

A total of 200 patients aged 60 years and above were considered for this study.

Xerosis was the most common physiological change seen in this study (90\%), which is similar to that reported in the study by Durai et al. $^{4}$ and few other Indian studies. ${ }^{5}$ The high prevalence of xerosis could be attributed to less use of emollients and usage of harsher soaps by the subjects who mostly hail from semi-rural areas. Wrinkling was the second most common change, and most of the wrinkling seen in this study was on sun-exposed areas, which is similar to most of other studies. ${ }^{6,7,8}$

In this study, eczematous conditions were seen in $44 \%$ patients. The suboptimal barrier functions of elderly skin associated with xerosis and pruritus were the common predisposing factors of the increased eczema prevalence in the elderly. Pruritus was the second most common finding in this study. The observed prevalence of pruritus in various studies ranged from $11.5 \%$ to $49.6 \%{ }^{4},{ }^{6,7}$

\section{CoNCLUSION}

Elderly patients are one of the more vulnerable sections of our society. Majority of the elderly in this study had xerosis and eczema.

\section{REFERENCES}

[1] Sheethal MP, Shashikumar BM. A cross-sectional study on the dermatological conditions among the elderly population in Mandya city. Int J Med Sci Public Health 2015;4:467-470 ferences

[2] World Health Organization. Good Health Adds Life to Years- Global Brief for World Health Day 2012. Geneva: World Health Organization, 2012. Available from: http://whqlibdoc.who.int/ hq/2012/WHO_DCO_WHD_2012.2_eng.pdf.

[3] United Nations. World Population Ageing 2013. New York: Department of Economic and Social Affairs, Population Division, United Nations, 2013. p. 96.

[4] Durai PC, Thappa DM, Kumari R, Malathi M. Aging in elderly: chronological versus photoaging. Indian J Dermatol 2012;57:343-52. 
Dermatological Conditions Among the Geriatric Population : a Cross Sectional Survey

[5] Raveendra L. A clinical study of geriatric [7] Grover S, Narasimhalu C. A clinical study of dermatoses. Our Dermatol Online 2014;5(3): 235-239. skin changes in geriatric population. Indian J Dermatol Venereol Leprol 2009;75:305-6.

[6] Tindall JP, Smith JG. Skin lesions of the aged and their association with internal changes. JAMA 1963;186:1039-42.

[8] Beauregard S, Gilchrest BA. A survey of skin problems and skin care regimens in the elderly. Arch Dermatol 1987;123:1638-43

Citation: Mubashar Mashqoor Mir, Mohammad Sarwar Mir. Dermatological Conditions Among the Geriatric Population : a Cross Sectional Survey. Archives of Dermatology and Skin Care. 2018; 1(1): 18-20.

Copyright: (C) 2018 Mubashar Mashqoor Mir, Mohammad Sarwar Mir. This is an open access article distributed under the Creative Commons Attribution License, which permits unrestricted use, distribution, and reproduction in any medium, provided the original work is properly cited. 